\title{
High Velocity Linear Induction Launcher with Exit-Edge Compensation for Testing of Aerospace Components
}

\author{
Stephen Kuznetsov ${ }^{1}$ and Darin Marriott ${ }^{2}$ \\ ${ }^{1}$ Power Superconductor Applications Corp., \\ ${ }^{2}$ Embry Riddle Aeronautical University
}

Advances in ultra high speed linear induction electromagnetic launchers over the past decade have focused on magnetic compensation of the exit and entry- edge transient flux wave to produce efficient and compact linear electric machinery. The paper discusses two approaches to edge compensation in long- stator induction catapults with typical end speeds of 150 to 1,500 $\mathrm{m} / \mathrm{s}$. In classical linear induction machines, the exit- edge effect is manifest as two auxiliary traveling waves that produce a magnetic drag on the projectile and a loss of magnetic flux over the main surface of the machine. In the new design for the Stator Compensated Induction Machine (SCIM) high velocity launcher, the exit- edge effect is nulled by a dual wavelength machine or alternately the airgap flux is peaked at a location prior to the exit edge.

A four (4) stage LIM catapult is presently being constructed for $180 \mathrm{~m} / \mathrm{s}$ end speed operation using double-sided longitudinal flux machines. Advanced exit and entry edge compensation is being used to maximize system efficiency, and minimize stray heating of the reaction armature. Each stage will output approximately $60 \mathrm{kN}$ of force and produce over $500 \mathrm{G}$ 's of acceleration on the armature. The advantage of this design is there is no ablation to the projectile and no sliding contacts, allowing repeated firing of the launcher without maintenance of any sort.

The paper shows results of a parametric study for $500 \mathrm{~m} / \mathrm{s}$ and $1,500 \mathrm{~m} / \mathrm{s}$ linear induction launchers incorporating two of the latest compensation techniques for an air-core stator primary and an iron-core primary winding. Typical thrust densities for these machines are in the range of $150 \mathrm{kN} / \mathrm{sq} . \mathrm{m}$. to $225 \mathrm{kN} / \mathrm{sq} . \mathrm{m}$. and these compete favorably with permanent magnet linear synchronous machines. The operational advantages of the high speed SCIM launcher are shown by eliminating the need for pole-angle position sensors as would be required by synchronous systems. The stator power factor is also improved.

\section{INTRODUCTION}

Under sponsorship from the British government, a team at Imperial College of Science and Technology, London pioneered the development of high-speed longitudinal flux machines for the high speed ground transportation program started by Tracked Hovercraft Ltd. Work in this area by Laithwaite, Kuznetsov, Greatorex, Bolton, and Attwood established the fundamental differences in linear machine design between longitudinal flux and transverse flux machines specific to continuousoperation propulsion machinery over the speed range $200 \mathrm{~km} / \mathrm{hr}$ to $480 \mathrm{~km} / \mathrm{hr}$ with typical module sizes of $30 \mathrm{MW}$. [1,2]

A primary objective of this work was to reduce the magnetic core dimensions and weight of the vehicle mounted primary structure for a system incorporating track mounted single and double-sided reaction rails. As of 1975, the highest rated longitudinal flux machine in the world was the Garrett-AiResearch LIMRV unit with a continuous-rated power density of 1.24 $\mathrm{kW} / \mathrm{kg}$ at a $112 \mathrm{~m} / \mathrm{s}$ upper speed. This double-sided, short-stator LIM had a $17 \mathrm{kN}$ rating at $173 \mathrm{~Hz}$, a pole-pitch of $0.355 \mathrm{~m}$ and a stator core depth which resulted in an overall stator weight of $1510 \mathrm{~kg}$. This machine was extensively tested at the 
USDOT Pueblo, CO High Speed Test Track and reported.

In 1992, Kuznetsov pioneered several new $105 \mathrm{~m} / \mathrm{s}$ linear motor designs for launching of aircraft as part of the Electromagnetic Aircraft Launch System (EMALS) program for the US Navy. These were long polepitch double-sided longitudinal flux machines with internal water cooling and fed by a 15 phase cyclo-converter at a 200 Megawatt power level. The system was arranged in 10 stages covering a $100 \mathrm{~m}$ launch zone and included an electrodynamic brake for stopping of the $1500 \mathrm{kG}$ shuttle after aircraft launch. [3]

Subsequent to the EMALS work, Power Superconductor developed a design for NASA for $250-500 \mathrm{~m} / \mathrm{s}$ launching of $10-30$ ton payloads to replace chemical propellants wherein the system included over $1 \mathrm{~km}$ of active stator units. The proposed energy source was inertial energy storage through a set of $3600 \mathrm{rpm}$ turbo-alternators each with a $500 \mathrm{MJ}$ output rating. A key objective was to improve the LIM power factor as this has large benefits for optimizing the entire system reactive power requirements and in lowering the overall weight of inverter and power conditioning apparatus.

Fig. 1 shows the stator winding for a set of 8 catapult LIMs currently being manufactured for NASA Dryden and Embry Riddle Aeronautical University with a $2.56 \mathrm{~m}$ long magnetic core and Class $\mathrm{H}$ form wound windings. The design operating speed is 180 $\mathrm{m} / \mathrm{s}$ with a synchronous speed of $225 \mathrm{~m} / \mathrm{s}$ and an upper frequency of $300 \mathrm{~Hz}$.

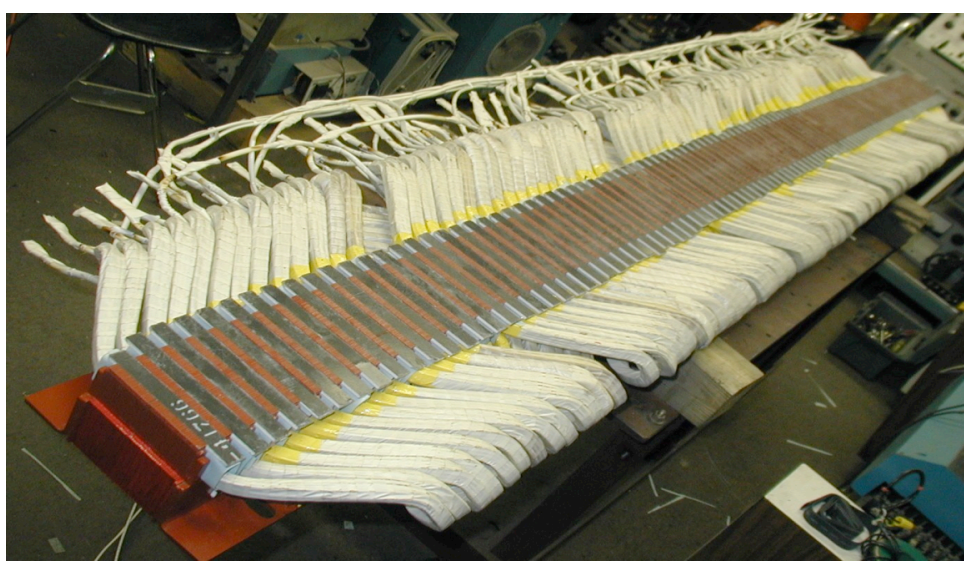

Fig.1 View of one stator of a D-LIM system being built for NASA and Embry Riddle University with 6 poles and $180 \mathrm{~m} / \mathrm{s}$ exit speed with Class $\mathrm{H}$ insulation.

The development of high speed linear induction motors is valuable from an aerospace component testing perspective not only because of smooth operation and low marginal cost but also because of other aerospace research which it could enable. Currently, experimental research related to flying air breathing engines such as ramjets, rocket combined cycle engines, dual cycle engines, air augmented rockets or other similar concepts is effectively beyond the capacity of non tier-one universities.

The extra requirements involved in acquiring first stage boosters, cannon launches, aircraft launches or similar first stages creates a large logistical and financial barrier for entry into supersonic experimental research. Because of the low marginal cost of operation, high speed linear induction catapults have the potential to allow for incremental testing of components and assemblies in a controlled environment so that complete systems need not be built each and every time. The long term objective is to grow a large number of smaller projects into operating EM-launch 
system while giving experience to aerospace students.

In 2006, Embry Riddle Aeronautical University collaborated with NASA Dryden on the purchase of two 2 Megawatt class double sided linear induction motors designed for $75 \mathrm{mph}$ operation. These units are currently being reconfigured to vertically launch a $2 \mathrm{~m}$ tall rocket. The new $180 \mathrm{~m} / \mathrm{s}$ four stage LIM under construction serves as a step toward development of large mass catapults and direct launching of air breathing vehicles without rockets or turbomachinery inside of the vehicle.

\section{NEW TECHNIQUES}

An electromagnetic technique known as Asynchronous Condenser (ASC) was implemented on a $3.5 \mathrm{~m}$ long, $0.5 \mathrm{~m}$ wide, short-stator LIM and showed terminal power factors of $80 \%$ at operating speeds of 20-80 $\mathrm{m} / \mathrm{s}$ and using a 9-phase, variable frequency (10-150 Hz) supply. [4] The ASC linear motors have dual pole pitches operating simultaneously and effectively reduce the exit edge effect, which has been a traditional cause for low power factor at high speeds. The classic exit- edge effect creates two undesirable transients, both of which can be attenuated by having a dual wavelength stator wound with a specified phase shift between low and high pole pitch sections.

The first ASC-LIM was single-sided, conduction-cooled with 600-volt class stator coils and had the unique feature of a doublewavelength two layer lap-wound stator winding to eliminate the classical exit-edge effect. This principal stator winding in slots No. 1-81 had a pole-pitch of $0.247 \mathrm{~m}$ and tertiary winding in slots $82-99$ had a polepitch of $0.205 \mathrm{~m}$ or $83 \%$ of the master wavelength. At high speed, the machine slip value is $6-12 \%$ and the tertiary winding performs as a reactive generator using what was previously wasted magnetic flux at the back of the machine. This reduces the flux at the exit-edge of the stator block to 0.40 p.u. of the traditional value of 0.60 Tesla thereby reducing the exit-edge magnetic drag losses to 0.16 p.u. of an uncompensated LIM. In the first longitudinal-flux ASC type LIM, the core weight is reduced to $60 \%$ of a conventional LIM block. The ASC concept raised the overall efficiency from $62 \%$ to $74 \%$ by a comprehensive system of design improvements centered on shifting the location of peak flux from the block end to two-thirds along the stator block. [5]

The ASC LIMs can attain an intermittent power density of $22 \mathrm{~kW} / \mathrm{kg}$ and steady-state power density of $7 \mathrm{~kW} / \mathrm{kg}$ with a liquid conduction-cooled stator.

Subsequently, a team at Power Superconductor built and tested a hybrid class of ASC wound catapult propulsion LIMs for a 6-12 ton passenger trains. These operate at a nominal acceleration is $1.5 \mathrm{G}$ 's up to a baseline speed of $45 \mathrm{~m} / \mathrm{s}$ then a tapering off of acceleration to $1.0 \mathrm{G}$ for the range, $45 \mathrm{~m} / \mathrm{s}-100 \mathrm{~m} / \mathrm{s}$. The peak thrust per module is $28-32 \mathrm{kN}$ at a speed of $45 \mathrm{~m} / \mathrm{s}$ representing a peak power output of 1.26 $1.44 \mathrm{MW} /$ module. Table 1 shows specifications for this machine as built for a Swiss roller coaster company whereby 6 modules are paralleled for a peak system output of 7.6 MW. The design is significant for EM catapults as it carries a $27.5 \mathrm{~kW} / \mathrm{kg}$ and 3.0 second rating with conduction/ convection cooling and a single-sided reaction rail composed of Type 6101-T64 aluminum.

The global merit factor for LIMs or TFMs is the Goodness Factor, $\mathrm{G}$ which is ratio of magnetizing reactance to reaction rail resistance and calculated as 


$$
\mathrm{G}=\frac{2 \mathrm{~T}_{\mathrm{p}}^{2} \mathrm{f} \mu_{\mathrm{o}} \mathrm{t}}{\pi \mathrm{P}_{\mathrm{r}} \mathrm{g}_{\mathrm{e}}}
$$

$\mathrm{T}_{\mathrm{p}}=$ pole-pitch

$\mathrm{f}=$ excitation frequency

$\mathrm{t}=$ reaction rail thickness

$\operatorname{Pr}=$ resistivity of rail

$\mathrm{g}_{\mathrm{e}} \quad=\quad$ electromagnetic airgap

The Goodness Factor $(\mathrm{G})$ or the product of slip x Goodness factor $(\sigma \mathrm{G})$ determines the ultimate performance, power factor, efficiency peak thrust and optimum operations slip values for each specific design.

Catapult type linear induction motors (C-LIM) are typified by very short operating times, high force density and force aircooled stators. The applications include electromagnetic mass launchers, rocket-sled for testing aircraft components, metal fabrication apparatus and roller coaster propulsion drives. The majority of applications have moving carriages with the secondary electrical member of reaction plate permanently attached to the carriage and have a longitudinal length less than the length of an array of LIM stators arranged in tandem. This constitutes a "short-secondary" system and a special design of the stator accommodates large differences in airgap permeance as a function of longitudinal position.

In a large high-speed catapult, the array of stator units is on the order of $100 \mathrm{~m}$ longitudinal and the reaction plate is usually between $2.0 \mathrm{~m}$ and $5.5 \mathrm{~m}$ in length. Force density for the C-LIMs is based upon the total active magnetic area of each stator surface; herein the C-LIM designs have a density of $36 \mathrm{kN} / \mathrm{sq} . \mathrm{m}$. The machines exhibit a constant thrust characteristic up to a base speed of, for example, $35 \mathrm{~m} / \mathrm{s}$ and then exhibit a constant power output characteristic in the high speed range.

Part of the rating scheme is based upon the inverter drive limitations; the C-LIMs presented here utilize IGBT variablevoltage, variable-frequency (VVVF) inverters with a peak current output of 1200 Amps at 515 Volts or $1070 \mathrm{kVA}$.

\section{MAGNETIC DESIGN}

High speed longitudinal flux LIMs designed for transport applications which have the LIM stator suspended from the vehicle carriage traditionally use seriesconnected stator windings. This results in a short-primary system whereby the airgap flux has an exponential rise in magnitude which becomes more pronounced as either the speed or Goodness Factor increases. [6] These short-primary schemes produce a phenomena known as exit-edge effect which results in magnetic drag at the tail end of the motor in proportion to the square of the airgap flux density.

Since catapult motors have very high flux densities in the airgap, typically in the range of 1.6 to 1.8 Tesla, it was important to reduce the magnetic drag component to a minimum. This was accomplished using a variation of a technique originally pioneered by Kuznetsov \& Laithwaite on large 100$150 \mathrm{~m} / \mathrm{s}$ class single-sided LIMs $[7,8]$. The magnetic circuit is reconfigured (by a drop in excitation MMF at the tail end of the machine) to produce the maximum flux density at a point 0.66 to 0.79 per unit along the stator surface. Fig. 2 shows a plot of airgap flux versus stator position showing the in-phase, quadrature and total airgap flux density as applied to a $500 \mathrm{~m} / \mathrm{s}$ LIM with a $50 \mathrm{~mm}$ airgap. 


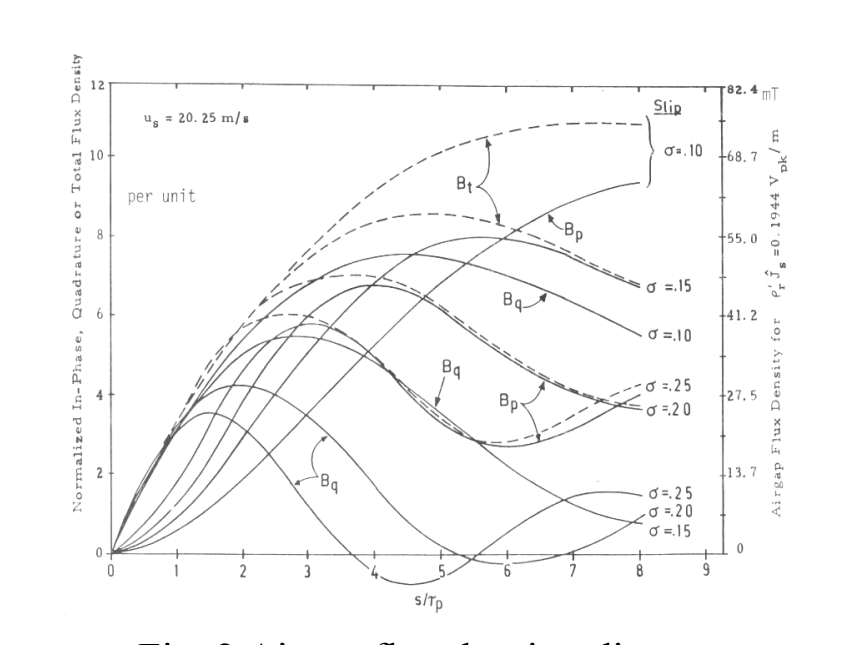

Fig. 2 Airgap flux density, direct $(\mathrm{Bp})$, quadrature $(\mathrm{Bq})$ and total $(\mathrm{Bt})$ components versus stator position "s" normalized to pole pitch for $\mathrm{G}=20$.

However, for the catapult short-secondary LIMs, it is a general design rule that the stator principally have parallel connected coils to force the airgap flux density distribution to have a near-constant flux amplitude as a function of longitudinal distance along the airgap. This is true for both constant frequency line- connected and inverter-connected supply systems feeding the LIM. The described catapult machines can have between 6 and 36 parallel coil groups in a 6-pole machine with the slots per pole per phase being as high as $\mathrm{q}=6$. The design constraints must account for the following magnetic design features:

1) The airgap normally-directed flux density should be optimized between 1.6 and 1.8 Tesla rms at any frequency and allow the magnetic teeth a degree of saturation at 2.2 to 2.4 Tesla rms. To accomplish this in an optimum fashion requires that each parallel phase group have multiple slots/pole/phase $(3,4,5$ or 6) in series connection to distribute the flux over a pole face.

2) The magnetic core of the LIM should be designed with a high level of flux density and attain at least 1.9 Tesla rms using an $\mathrm{M}$ 15, or Hiperco-50 lamination steel. The laminations may be sized thicker than conventional up to a value of 25 mils since the core loss component is only on for a 2.0 second period

3) The use of multiple slot/pole and phase coil windings also reduces stray load loss in inverter driven supplies and allows for a more even distribution of flux in the airgap with supplies that have principally square-wave voltage output. The LIM magnetic design differs from a rotary design in that the stator teeth are much narrower. The dimensioning relates to the ratio of tooth width: airgap which in a linear machine should be in the range of 0.30 to approximately 0.66 per unit. Typical airgaps in a double-sided catapult LIM will be 15 to 27 $\mathrm{mm}$ and the secondary member will be respectively either 6.3 $\mathrm{mm}$ or $10 \mathrm{~mm}$ thick aluminum plate.

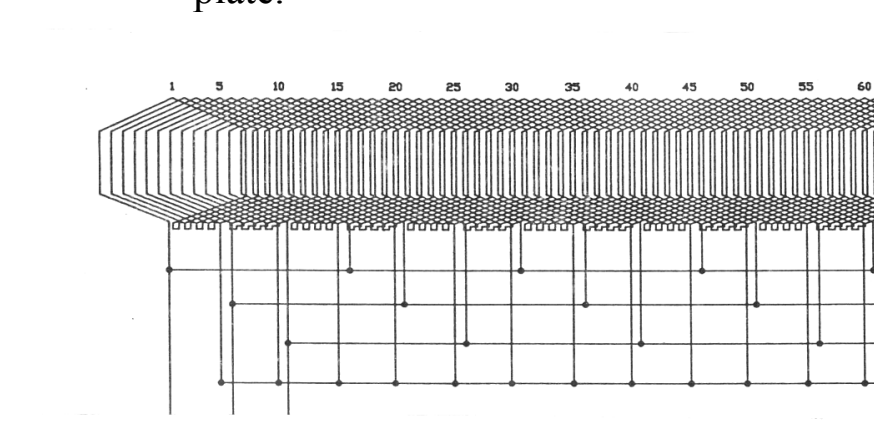

Fig. 3 Stator winding layout for aircraft launch catapult linear motor for $125 \mathrm{~m} / \mathrm{s}$ and higher speeds. 
4) Test results on C-LIMs with pole-pitches over $0.250 \mathrm{~m}$ indicate that the end-windings do contribute to positive force production. The $300 \mathrm{~Hz}$ wound catapult units require polepitches of $0.381 \mathrm{~m}$ to $0.480 \mathrm{~m}$ to attain synchronous speeds of 180 $\mathrm{m} / \mathrm{s}$ to $226 \mathrm{~m} / \mathrm{s}$. With these large pole pitches, the transversedirected component of the end winding flux contributes to overall force production.

\section{C-LIM CONSTRUCTION}

Catapult machines are built to produce acceleration forces up to $600 \mathrm{G}$ 's and have specially designed stator windings to hold up in service for launch duty. Table 1 shows a representative design. Several special design features include:

1) Form-wound, square cross-section copper wire Type HTP with a Class $\mathrm{H}$ insulation, vacuum pressure impregnation, epoxy based useable to $180^{\circ} \mathrm{C}$.

2) Laser-cut finger plates to provide positive transverse clamping of the magnetic core and of the fingers.

3) Double constant-pressure core clamping fixtures on the stator incorporating aircraft type L9 clamping bolts rated at 175 KSI yield strength.

4) Stator leads are silver-alloy brazed and end-windings are designed to an extremely tight overhang dimension so as to yield a monolithic overhang structure and a minimum of airspace in the end-winding region.

5) On select units, the stator is encapsulated on 4 sides and the top surface by a stainless steel tray of thickness $1.5 \mathrm{~mm}$ for the purpose of mechanical protection to the stator upper surface. This conductive tray does contribute to higher than normal no-load losses and will dissipate typically $3.5 \mathrm{~kW}$ per motor rated at $241 \mathrm{~kW}$.

Table 1

Type H C-LIM Characteristics for Catapult Linear Induction Motor

$\begin{array}{ll}\text { Continuous Power Output } & 482 \mathrm{~kW} \\ \text { Peak Power Output } & 1266 \mathrm{~kW} \\ \text { Overall Length } & 2.565 \mathrm{~m} \\ \text { Overall Width } & 425 \mathrm{~mm} \\ \text { Operating Speed } & 180 \mathrm{~m} / \mathrm{s} \\ \text { Inverter Freq Output } & 300 \mathrm{~Hz} \\ \text { Apparent Power Input } & 744 \mathrm{kVA} \\ \text { Power Factor } & 0.81 \mathrm{p.u} . \\ \text { Active Surface Area } & 0.257 \mathrm{sq} . \mathrm{m} . \\ \text { Peak Thrust at } 50.6 \mathrm{~m} / \mathrm{s} & 25 \mathrm{kN} \\ \text { Thrust at } 180 \mathrm{~m} / \mathrm{s} & 7.0 \mathrm{kN} \\ \text { No. Of Pole-Pitches } & 6 \\ \text { No. Of Poles }- \text { Entry/Exit } & 4 / 2 \\ \text { Average Pole-Pitch } & 381 \mathrm{~mm} \\ \text { Temperature Rise/shot } & 15^{\circ} \mathrm{C} \\ \text { Force Density } & 97,300 \mathrm{~N} / \mathrm{sq} . \mathrm{m} .\end{array}$

The double-sided stators are mounted in a C-frame housing $325 \mathrm{~mm}$ high and $308 \mathrm{~mm}$ high constructed of welded A500-B steel box beams. The main structural ribs are composed of ASTM Type A572. This construction provides for a rigid frame and minimized lateral and vertical deflections of the frame during a shot. The worst case vertical deflection of the frame components was measured at 6 mils maximum deflection with a natural frequency for each stator assembly of 170$273 \mathrm{~Hz}$. The worst case condition appears when there is no reaction rail present and the attractive force attains a maximum based upon the vertical directed specific force density of :

$\mathrm{F}=\mathrm{B}^{2} / 2 \mu_{\mathrm{o}}=657 \mathrm{kN} / \mathrm{sq} . \mathrm{m} . @ \mathrm{~B}=1.6 \mathrm{~T}$

Fig. 3 shows the stator winding layout for an aircraft-launch catapult LIM in 12 poles and series-parallel connected phase groups valid for $125 \mathrm{~m} / \mathrm{s}$ and higher speeds. 


\section{TEST RESULTS}

Testing and certification of the CLIMs has been accomplished with National Instruments "Labviews" virtual instrumentation software. This has rapid 12bit data acquisition and includes exact determination of the asymmetrical current waves on the first 4 cycles of energization to be able to determine the $\mathrm{X} / \mathrm{R}$ ratio and surge impedance of the motor from test. The Labviews digital virtual instrumentation system monitors 6 currents, thrust, voltage, temperature rise and magnetic sensors on a 515 Volt input. Shown is test data taken on a $9 \mathrm{kN}$ thrust LIM of 0.250 sq.m. surface area used as a catapult motor for a 6 ton load.

Fig. 4 shows the $60 \mathrm{~Hz}$ certification tests on a double-sided catapult LIM of 2.0 $m$ active length whereby both top and bottom stators are individually instrumented for current, reactive power, real power and flux density. These tests were performed with aluminum type 1100 reaction rail, 6.3 mm thick. A shunt capacitor bank of 100 kVARs was used. The peak power factor attained for the motor alone was $81 \%$ and the measure acceleration was $435 \mathrm{G}$ 's on a $10 \mathrm{~kg}$ mass.

The waveforms show a peak terminal current of 1100 Amps per side at 390 volts during the launch with an input apparent power of $1051 \mathrm{kVA}$. Slip was measured optically and was maintained at a high value for the purpose of operating the machine close to the maximum thrust pull-out slip of which is calculated approximately [5] as

$\delta=1 /(\mathrm{n}+1)=1 / 7$

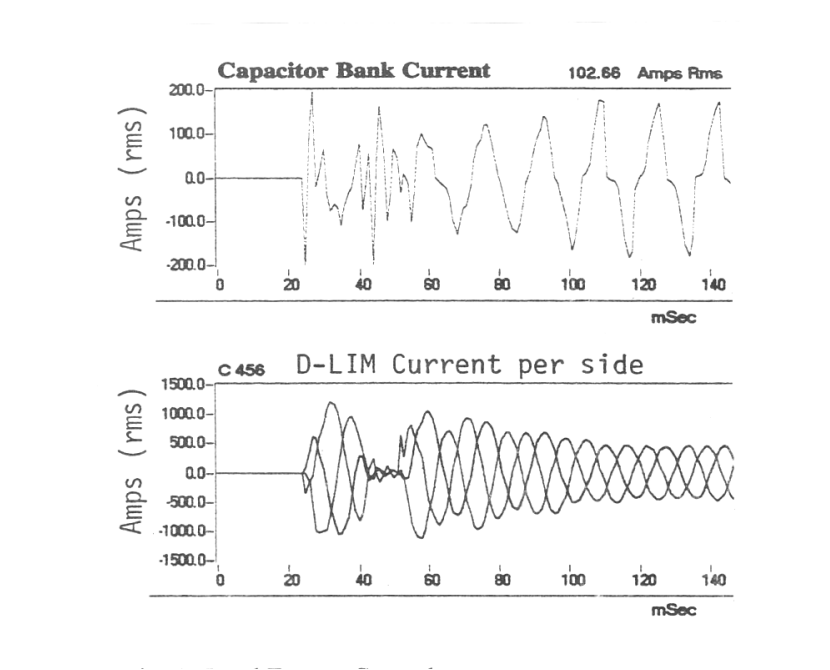

Fig. 4 Load Test on D-LIM Catapult

where $n=$ number of stator total poles (6) for both entry and exit poles. The maximum differences in phase currents for the combined upper or lower stator units is $7 \%$ during peak acceleration mode. The reactive power input varies by $+/-8 \%$ among phases; the real power input varies by $+/-6 \%$ among phases. A major design consideration in certifying performance is the regulation of the input power supply which in the case of the described C-LIM tests, the power line transformers have a combined line impedance of $11 \%$. The line voltage drops from $515 \mathrm{~V}$ rms to 390 volts rms during a catapult launch with 435-466 G acceleration.

The power factor is significantly lower at $30 \%$ and the phase current balance has a $+/-$ $4 \%$ variation. During theses tests, the peak vertical attractive force between the two stators is about at $800 \mathrm{~N}$ based upon an airgap of $22 \mathrm{~mm}$. The DC waveform offset on the first two cycles indicates that the $\mathrm{X} / \mathrm{R}$ ratio of this LIM is 15:1 at initial magnetization. 


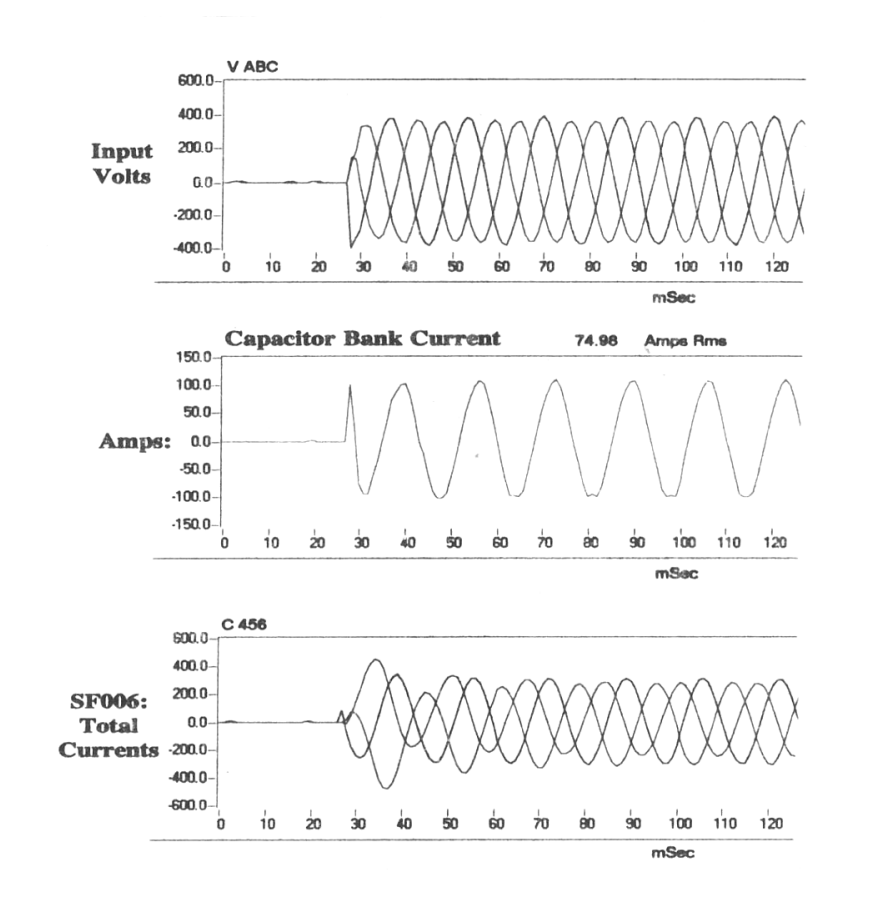

Fig. 5 Magnetizing Tests at 500 Volts

Fig. 5 shows the corresponding test on the 9 $\mathrm{kN} \mathrm{C}$-LIM for magnetizing and no-load losses from a 500 Volt $60 \mathrm{~Hz}$ source.

\section{CONCLUSIONS}

New techniques to attenuate the exit- edge effect in $200 \mathrm{~m} / \mathrm{s}$ to $500 \mathrm{~m} / \mathrm{s}$ linear induction machines result in an excitation structure with multiple wavelengths and careful selection of the stator block length to avoid core flux modulation. A technique now in practice is to maintain the direct axis flux high and have a negative value of quadrature flux at a point of about $66 \%$ along the stator block to maximize power factor and performance at very high speeds. Further improvements include 6 and 9 phase windings which lower the exit-edge flux density to a level about $30 \%$ of the peak which results in a $91 \%$ reduction in magnetic drag at the tail end of the machine.

These improvements allow high frequency machines operating at 500 to $1500 \mathrm{~m} / \mathrm{s}$ to be economic to manufacture for aerospace component test catapults and eventual use for launching air breathing vehicles.

\section{ACKNOWLEDGMENT}

The authors acknowledge the financial support of the National Aeronautics \& Space Administration, Dryden Flight Research Center under the direction of Kurt Kloesel.

\section{REFERENCES}

[1] E.R. Laithwaite, et.al., "Linear Motors with Transverse Flux," Proc. IEE(UK), Vol. 118, No. 12, Dec. 1971, pp. 1761-1767.

[2] S.B. Kuznetsov and E.R. Laithwaite, "Reactive power Generation in High Speed Induction Machines by Continuously Occurring Space Transients," IEEE Magnetics, Vol. MAG-16, No. 5, 1980, pp. 716-718.

[3] S.B. Kuznetsov, "Final Technical ReportElectromagnetic Aircraft Launch System, NAVAIR Contract No. N68335-90-C-0346, 1992.

[4] E.R. Laithwaite and S.B. Kuznetsov, "The Asynchronous Condenser: A Brushless Adjustable Power Factor Induction Machine," IEEE Trans Power Apparatus \& Systems, Vol. PAS-99, No.6, Nov. 1980.

[5] E.R. Laithwaite and S.B. Kuznetsov, "Power Factor Improvement in Linear Induction Motors," Proc. IEE, Vol. 128, Pt.B., No. 4, July 1981, pp. 190-194.

[6] E.R. Laithwaite, "The Goodness of a Machine,” Proc. IEE (UK), Vol. 112, No. 3, pp. 538-541, 1965.

[7] U. S. Patent No. 5,483,111, assigned to Power Superconductor Applications Corp. [8] European Patent Specification No. 0-025297, Improvements in Electrical Machines, 1985. 